\title{
Molecular Analysis of H5N1 Avian Influenza Virus from Avian Species: Compared with Genbank Data of the Indonesian H5N1 Human Cases
}

\author{
NI LUH PUTU INDI DHARMAYANTI \\ Virology Department, Balai Besar Penelitian Veteriner, Jalan RE Martadinata 30, Bogor 16114, Indonesia \\ Phone: +62-251-8331048, Fax:+62-2518336425,E-mail:nlpdharmayanti@yahoo.com
}

\begin{abstract}
In Indonesia, the H5N1 avian influenza (AI) disease has been circulating for more than five years and has infected various types of avian species and human beings. Generally, avian influenza cases in human beings are suspected to be spread by chicken, birds or waterfowl previously infected by avian influenza. The data supporting this assumption were very limited, therefore the molecular characterization on four avian influenza genome segments such as hemagglutinin, neuraminidase, matrix and non structural that was isolated from the avian species surrounding the avian influenza cases in human was conducted. The analysis was conducted on these genes which were responsible for binding receptors, the pathogenicities, and the resistance to antiviral drugs, thus the virus changes can be detected by comparing the sequence data of GenBank from human cases related to the avian species. The four avian influenza viruses used in this study isolated from avian influenza cases surrounding the avian influenza cases in human in 2007. The results of genetic analysis showed that these four viruses and the available sequence data from the GenBank for of avian influenza virus in human and avian have the receptor $\alpha-2,3$ of sialic acid which is the avian receptor. The $\mathrm{A} / \mathrm{Ck} / \mathrm{West}$ $\mathrm{Java/Bks2/2007}$ virus is collected from the chicken surrounding the avian influenza cases in human that resembles the data of avian influenza virus from human, A/Indonesia/CDC1031/2007 from GenBank. The viruses conferred similarities amino acid sequence of hemagglutinin, neuraminidase, matrix and non structural protein. All viruses used have deletion at the position 80-84 of the NS1 protein and possessed the ESEV motif which may contribute to an increased virulence. The avian influenzaviruses examined in this study also show resistance to amantadine.
\end{abstract}

Key words: Avian influenza H5N1, avian species, surrounding human cases

Influenza A virus can be isolated from various living creatures such as human, swine, horses, water poultry, chickens, sea mammals, and camels. The evolution of the Avian Influenza virus (AIV) occurs continuously and mostly on the surface of the glycoprotein of the virus, however, it may also occur on other gene segments. The variation of this virus is an accumulation of molecular changes of eight RNA segments that may occur through point mutation (antigenic drift), gene reassortment (antigenic shift), defective-interfering particles, and RNA recombination. Each mechanism contributes to the evolution of the Avian Influenza virus (Webster et al. 1992).

In Indonesia, the AI disease has been circulating for more than five years and has infected various species (Dharmayanti et al. 2005a, 2005b, 2005c). In July 2005, this virus caused the first death of a human victim infected by the H5N1 subtype of AI virus. In September 2005 it was also reported that avian influenza virus attacked several birds not only at Ragunan Zoo but also at Tegal Alur Bird Sanctuary (Dharmayanti et al. 2006). The mutation that comprises substitution, deletion and insertion is one of the most important mechanisms in producing variations of the influenza virus. Failure in proofreading of the RNA polymerase has a role in the replication error, which is around base 1 in every $10^{4}$ base (Holland et al. 1982; Stainhauer and Holland 1987).

Most of the human infected by the H5N1 virus in Indonesia resulted fatal cases. At 27 January 2009 a sum of 115 people died due to this virus. So far the infection occurring in human has been assumed to come from poultry surrounding the victims area. There are no profound scientific data supporting this assumption. In this study, molecular analysis was conducted to compare the virus genetic substance collected from birds surrounding the AI cases in human. Molecular characterization was conducted on four (NA, HA, M and NS) out of eight AI genome segments as these genes are responsible for binding receptor, pathogenicity, and resistance to antiviral drugs, thus the virus characters can be detected by comparing the sequence of the data of the GenBank of the AI cases in human related to avian species.

\section{MATERIALS AND METHODS}

AI Virus. The four avian influenza viruses analyzed in this study were successfully isolated from the avian species (bird and chicken) surrounding the human beings infected by AI virus H5N1 subtype in 2007 as presented in Table 1 (Dharmayanti et al. 2004, 2005, 2006) were then further analyzed by conducting sequencing on four segments, namely, hemagglutinin (segment 4), neuraminidase (segment 6), matrix (segment 7) and nonstructural (segment 8). The viruses were propagated in Specific Pathogen Free (SPF) eggs that have embryos aged 9-11 days (OIE 2000).

Reverse Transcriptase-Polymerase Chain Reaction (RTPCR). Total RNA were extracted from infected allantoic fluid was extracted using commercially available QIAamp RNA mini kit (Qiagen). The RT-PCR reaction was conducted using the Superscript one Step RT-PCR System (Invitrogen) according to the manufacturer's instruction using the Thermal Cycler Applied Biosystem 9700 machine. The primers used to amplify the four AI virus segments were in accordance with Hoffmann et al. (2001).

DNA Sequencing and Genetic Analysis. The amplified DNA obtained was purified by using the QIAquick PCR purification kit (Qiagen). The sequencing method used was the direct sequencing with the Cycle sequencing kit (BigDye Terminator version 3.1; Applied Biosystem) using the Genetix Analyzer 3310 machine (Applied Biosystem). The fragment 
Table 1 AI viruses were collected from avian species surrounding influenza H5N1 cases in human that were used in this study

\begin{tabular}{lll}
\hline Name of virus & AI human cases location & Victims suspect/confirm AI \\
\hline A/Ck/Jakarta/Walkot 1/2007 & Kompleks Walkot, Jakarta & Mr. A (suspect, negatif) \\
A/Bird Cucak Wilis/Jakarta/Walkot 4/2007 & & \\
A/Ck/Jakarta/Jakbar-onh2007 & Kalideres, Jakarta & R (confirm, positif) \\
A/Ck/West Java/Bks2/2007 & Bekasi & $7-8$ (confirm, positif) \\
\hline
\end{tabular}

assembly and sequence editing were conducted by using the Bioedit. Multiple alignment production was conducted using the Clustal W program (www.ebi.ac.uk). The DNA sequences were translated into amino acid sequences and subjected to multiple alignments using Bioedit program, and further constructed into a phylogenetic MEGA 4, program available from www.megasoftware.net.

\section{RESULTS}

Molecular Analysis on the Hemagglutinin (HA) Gene. The four virus isolates analyzed in this study show that only one isolate, the $\mathrm{A} / \mathrm{Ck} / \mathrm{West} \mathrm{Java} / \mathrm{Bks} 2 / 2007$ is within the same group with the sequence data of the isolate in human cases (Fig 1). This isolate does not have close relationship with the avian isolates analyzed in this study.

The A/Ck/West Java/Bks2/2007 virus was collected on 12 January 2007 after it was reported that there were eight of the AI suspected patients aged 6-15 old years in Bekasi district. Prior to this accident, at the same location the chicken and muscovy duck owned by one of the inhabitant (M) died. The A/Ck/West Java/Bks2/2007 isolate was collected from the remaining live chickens owned by $M$. There was no information regarding the location of the human isolates at the GenBank, in this study the case possibilities were traced (based on the dates of sample collections) to find out whether $\mathrm{A} / \mathrm{Ck} / \mathrm{West} \mathrm{Java} / \mathrm{Bks} 2 / 2007$ virus is the virus in infected human area. The complete data on human isolates that have close relationship with the A/Ck/West Java/Bks2/2007 virus included four samples were collected in January 2007 are presented in Table 2. However, considering the victims' ages

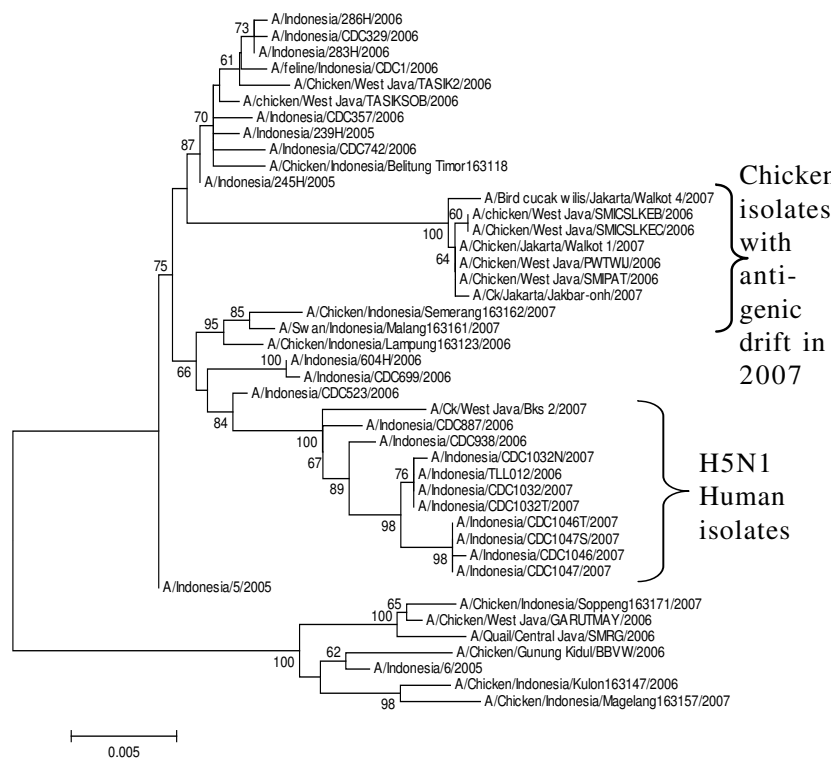

Fig 1 Phylogenetic tree of HA gene of influenza H5N1 viruses from human and animal. Three isolates were same group with antigenic drift isolate in 2006 that showed antigenic drift and one isolate (A/Ck/West Java/Bks2/2007) have same group with H5N1 human isolates. the of A/Indonesia/CDC1031/2007 virus has the greatest possibility and relatedness to the A/Ck/West Java/Bks2/2007 virus.

The A/Ck/Jakarta/Walkot 1/2007 and A/Bird Cucak Wilis/ Jakarta/Walkot 4/2007 isolates were collected on 11 January 2007; an adult male without possession of chickens or another avian species was the AI suspect patient (J). Therefore, the samples were collected from the surrounding location and from his neighbors. Until this report was written, the writer had not received any information whether the patient was infected or not. The A/Ck/Jakarta/Jakbar-onh/2007 isolate was collected from the surrounding location (neighbor) of a positively confirmed AI case (R). The samples taken from the birds raised at R's house showed negative results. Three isolates, A/Ck/Jakarta/Walkot 1/2007, A/Bird Cucak Wilis/ Jakarta/Walkot 4/2007 and A/Ck/Jakarta/Jakbar-onh/2007 did not show genetic closeness to the human data sequence infected by AI from the GenBank but they showed their closeness to other avian isolates which experienced quite significant mutation compared with other avian isolates. Throughout 2006, the highest mutation was of two H5N1 viruses, namely the A/Ck/West Java/Pwt-Wij/2006 and Ck/ WestJava/Smi-Pat/06 which amounted to $4.88 \%$. Both viruses were taken from the flocks of a poultry farm that conducted AI vaccination. However, in the analysis of HA gene, the three isolates used in this study A/Ck/Jakarta/Walkot 1/ 2007, A/Bird Cucak Wilis/Jakarta/Walkot 4/2007 and A/Ck/Jakarta/Jakbar-onh/2007 showed that they were in the same group as the isolates collected in 2005-2006, which were A/Indonesia/CDC292/2005, A/Indonesia CDC742/2006, and A/Ck/west Java/Tasiksob/2006 viruses.

The multiple sequence alignment of the A/Ck/West Java/ Bks2/2007 and A/Indonesia/CDC1031/2007 viruses only differ in 2 amino acids, which are Lys/K at position 35, and $\mathrm{Thr} / \mathrm{T}$ at position 513 in the A/Indonesia/CDC1031/2007 isolate which replace $\mathrm{Arg} / \mathrm{R}$ and Lys/Lin $\mathrm{A} / \mathrm{Ck} / \mathrm{West} \mathrm{Java} / \mathrm{Bks} 2 / 2007$ virus (Fig 2). The A/Ck/Jakarta/Walkot1/2007, A/Bird Cucak Wilis/ Jakarta/Walkot4/2007 and A/Ck/Jakarta/Jakbar-onh/2007 viruses have 17-18, amino acid substitution similar to those of the A/Ck/West Java/Pwt-Wij/2006. These differences cause the virus group form a significantly different group from other AI viruses. The A/Ck/West Java/Pwt-Wij/2006 is a virus successfully found at the flock that has been exposed

Table 2 Data from GenBank based on phylogenetic analysis that have close relationship with virus of A/Ck/West Java/Bks2/2007

\begin{tabular}{|c|c|c|}
\hline AI viruses & $\begin{array}{l}\text { Gender/Age } \\
M / F \text { (years) }\end{array}$ & $\begin{array}{c}\text { Date of sample } \\
\text { collection }\end{array}$ \\
\hline A/Indonesia/CDC1031/2007 & M (14) & 5 Jan 2007 \\
\hline A/Indonesia/CDC1032/2007 & F (37) & 7 Jan 2007 \\
\hline A/Indonesia/CDC887/2007 & M (12) & 14 Oct 2006 \\
\hline A/Indonesia/CDC938/2007 & $F(35)$ & 10 Nov 2006 \\
\hline A/Indonesia/CDCTL012/2006 & No information & \\
\hline A/Indonesia/CDC1046/2007 & $\mathrm{F}(22)$ & 11 Jan 2007 \\
\hline A/Indonesia/CDC1047/2007 & $\mathrm{F}(26)$ & 12 Jan 2007 \\
\hline
\end{tabular}


to AI vaccination using H5N2. This possibly happened due to the immunological pressure received by the virus, thus the virus appeared as an escape mutant. All the data on the viruses analyzed at the cleavage site of HA protein at the amino acid position 321-330 in this study show Highly Pathogenic Avian Influenza (PQRESRRKR//GLF) and have Ser/S at position-6 of HA1.
The analysis of the pocket receptor binding site did not show any changes, such as $91(\mathrm{Tyr} / \mathrm{Y}), 130-134(\mathrm{Gly} / \mathrm{Val} / \mathrm{Ser} /$ Ser/Ala/GVSSA), 149(Trp/W), 151(Ile/I), 179(His/H), 186(Glu/ E), 190(Leu/L) and 191(Tyr/Y). All data on the viruses analyzed showed that they were familiar with $\alpha-2,3$ of sialic acid which is an avian receptor, the QSG (222-224), and none was familiar with the human receptor, the LSS (222-224).
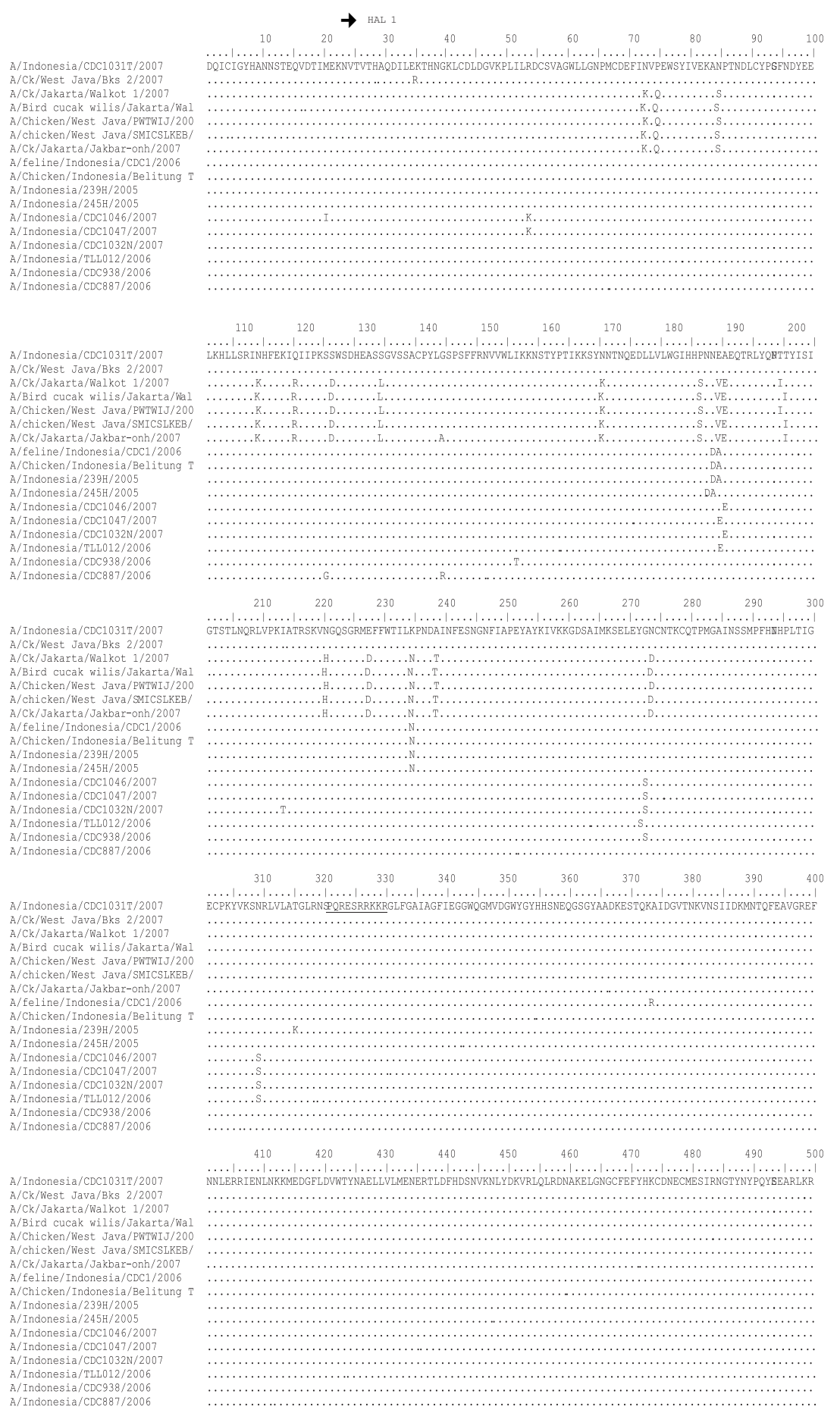

A/Indonesia/CDC1031T/2007 A/Ck/Jakarta/Walkot $1 / 2007$ A/Bird cucak wilis/Jakarta/Wal
A/Chicken/Viest Java/PuirhI A/chicken/West Java/SMICSLKEB, A/CK/Jakarta/Jakbar-onh/2007
A/feline/Indonesia/CDC1/2006

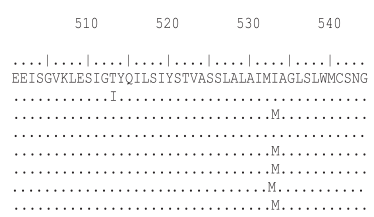

Fig 2 Multiple sequence alignment of amino acid of HA protein AIV surrounding AI human cases. Sequence amino acids at the cleavage site of HA were underlined. 
Molecular Analysis on the Neuraminidase (NA) Gene. Most of Indonesian AI viruses, both isolated from animals and human, do not experience changes or mutations in the NA gene such that of the HA gene. However, the A/Ck/West Java/Bks2/2007 isolate on the HA gene level is the closest virus to the AI virus of human origin in 2007, especially the A/Indonesia/CDC1031/2007 virus. Meanwhile, the three other isolates have their closeness to the AI virus of human origin in 2005-2006 (Fig 3).

The results of analysis on the multiple sequence alignment of neuraminidase amino acid composition between the $\mathrm{A} / \mathrm{Ck} /$ West Java/Bks2/2007 and A/Indonesia/CDC1031/2007 viruses did not show any difference. The viruses of $\mathrm{A} / \mathrm{Ck} /$ Jakarta/Walkot1/2007, A/Bird Cucak Wilis/Jakarta/Walkot4/ 2007 and the A/Ck/Jakarta/Jakbar-onh/2007 have a similar amino acid composition to that of the A/Indonesia/7/2005 and several others; but only at the position where $320 \mathrm{Ser} / \mathrm{S}$ replaces Pro/P (Data not shown).

Molecular Analysis on the Non Structural (NS) Gene. As in the NA gene, at the NS gene molecular level the AI viruses in human and animals do not show significant differences. The A/Ck/West Java/Bks2/2007 virus consistently shows its closeness to A/Indonesia/CDC1031/ 2007 virus. Aside of the A/Indonesia/CDC1031/2007, the A/ Indonesia/604H/2006 and A/Indonesia/CDC523/2006 viruses show their genetic closeness at the NA gene level. The other three viruses, such as A/Ck/Jakarta/Walkot 1/2007, A/Bird Cucak Wilis/Jakarta/Walkot 4/2007 and A/Ck/Jakarta/Jakbar- onh/2007 also consistently show their closeness to the AI virus in human in 2005-2006 (Fig 4). At the NS gene level the AI virus of China or Hong Kong origins show a very significant difference as it is not within the same group as the viruses of Indonesian origin.

The multiple sequence alignment analysis on the non structural protein (Fig 5) shows that there were only four different amino acids (position 59, 124, 205 and 242) between the A/Ck/West Java/Bks2/2007 and A/Indonesia/CDC1031/ 2007 viruses. Three other viruses have almost the same amino acid compositions as those of the AI virus of Indonesia origin in 2005-2006.

Large-scale sequence analysis of avian influenza viruses indicated that the four $\mathrm{C}$-terminal residues of the NS1 protein is a potential PDZ- ligand binding motif of the X-S/T-X-V type (Obenauer et al. 2006). PDZ-ligand binding motifs with the ESEV or EPEV sequence were found in the NS1 protein from HPAI H5N1 viruses isolated in 1997 and 2003, as well as the 1918 pandemic virus (all of avian origin). In this study, all of the viruses used possessed ESEV motifs (Fig 5).

Molecular Analysis on Matrix (M) Gene. The analyses of the $\mathrm{M}$ gene show that A/Ck/Jakarta/Walkot1/2007, A/Bird Cucak Wilis/Jakarta/Walkot4/2007 and A/Ck/Jakarta/Jakbaronh/2007 viruses have genetic closeness to the human origin virus of 2007, namely A/Indonesia/CDC1046/2007 and A/ Indonesia/CDC1047/2007, and are within the same group as the A/Ck/West Java/Bks2/2007 and other human origin viruses. At the level of the $\mathrm{M}$ gene, the four viruses used in

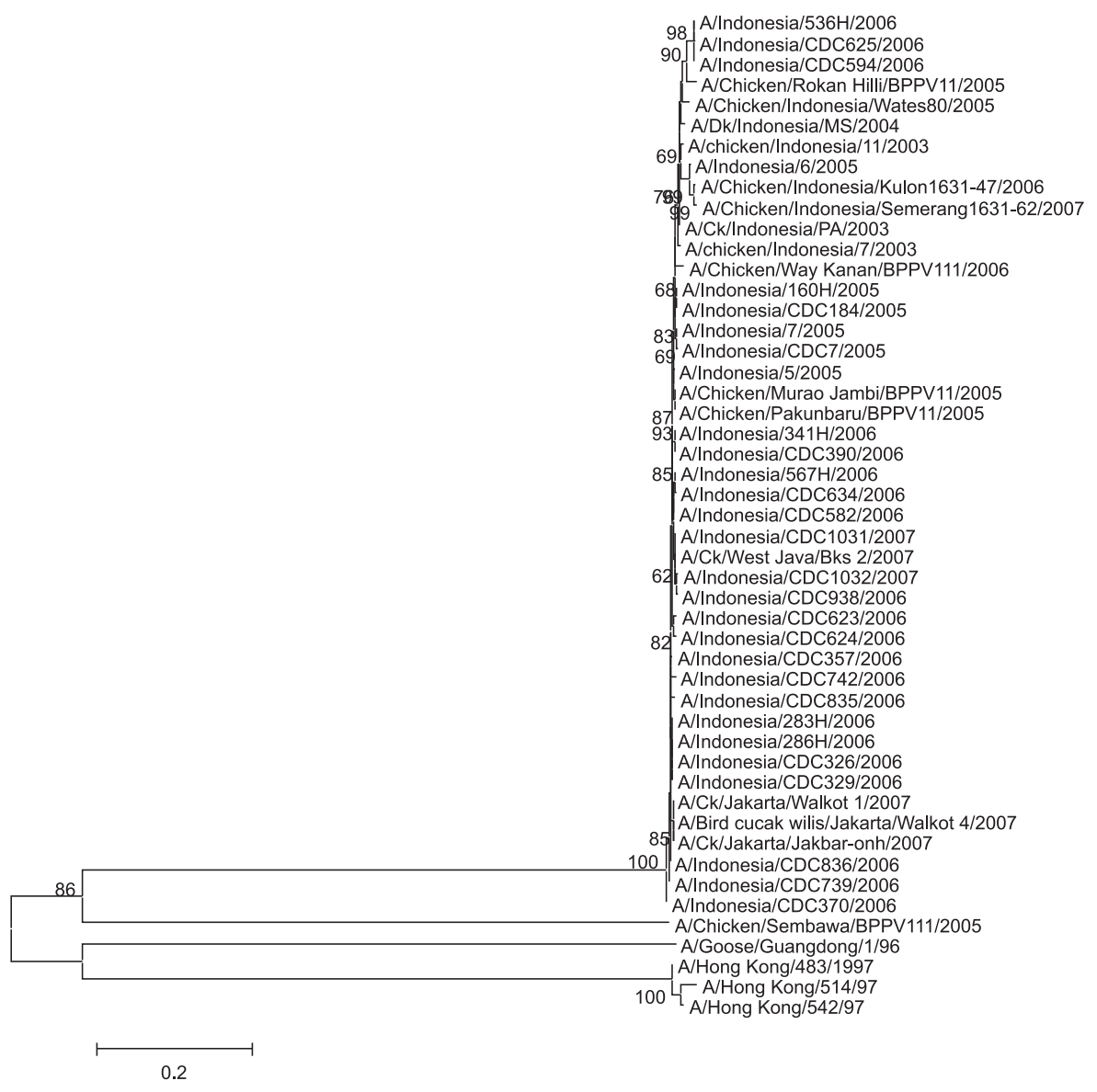

Fig 3 Phylogenetic tree of NA gene of influenza H5N1 viruses from human and animal. 


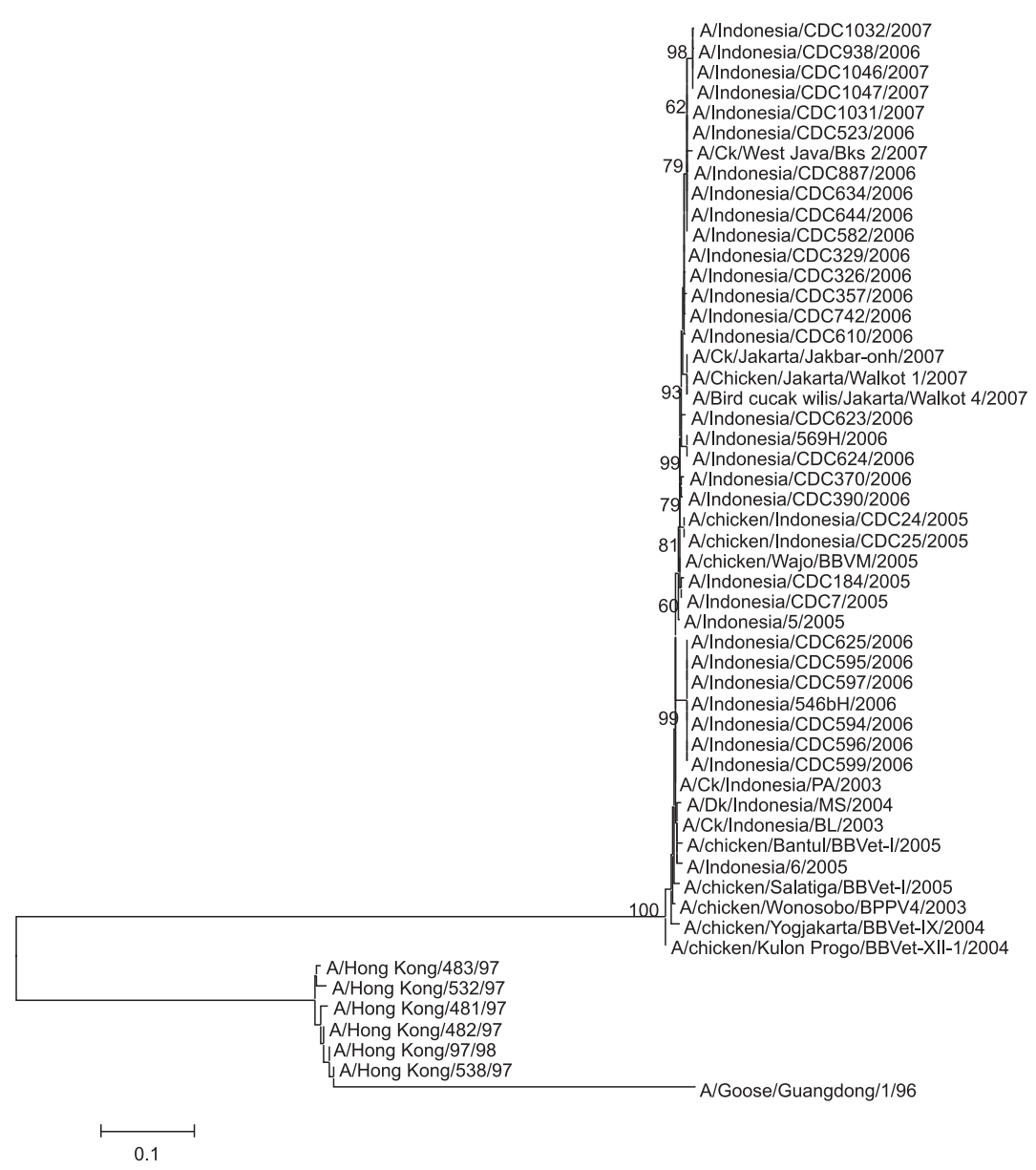

Fig 4 Phylogenetic tree of NS gene of influenza H5N1 viruses from human and animal.

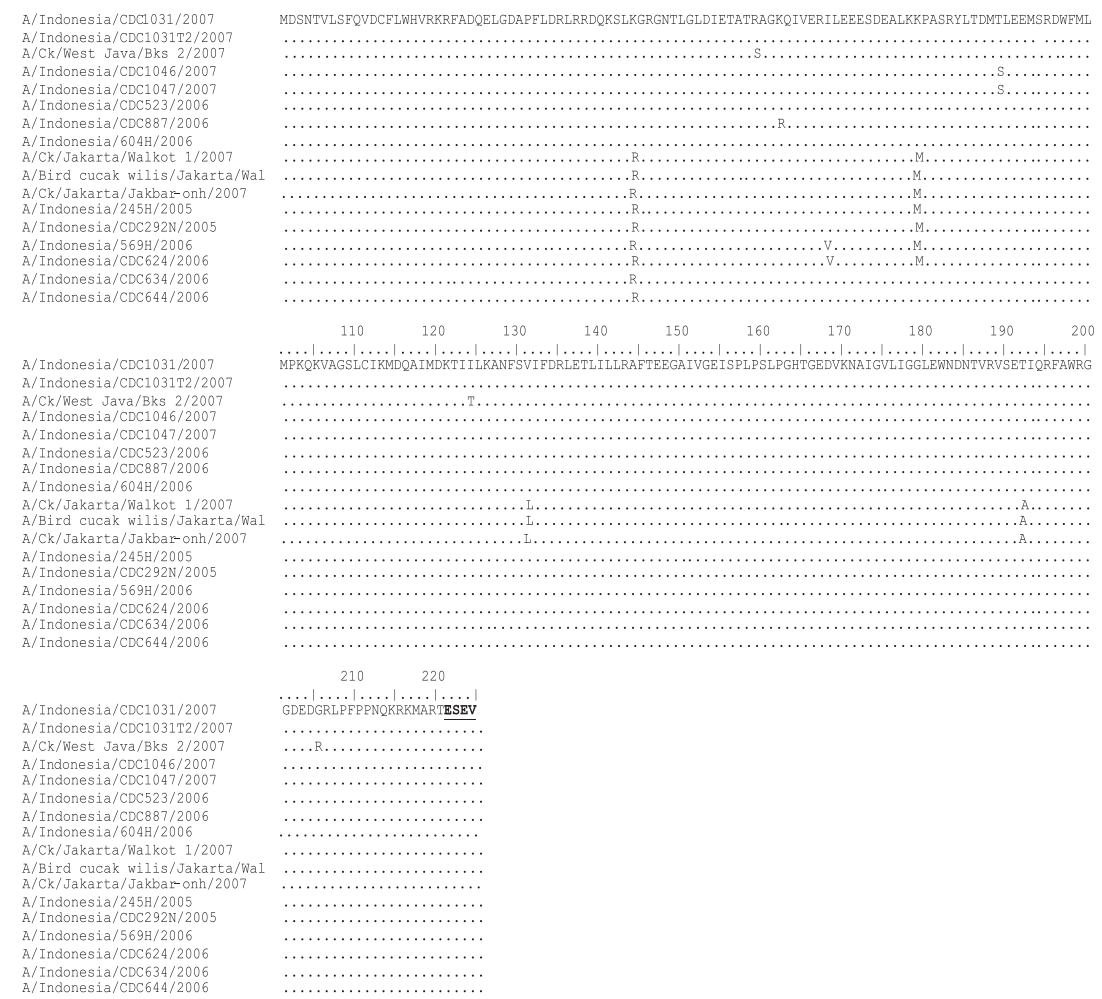

Fig 5 Multiple sequence alignment of amino acid of NS protein AIV surrounding AI human cases. The PDZ-ligand binding motif was underlined. 


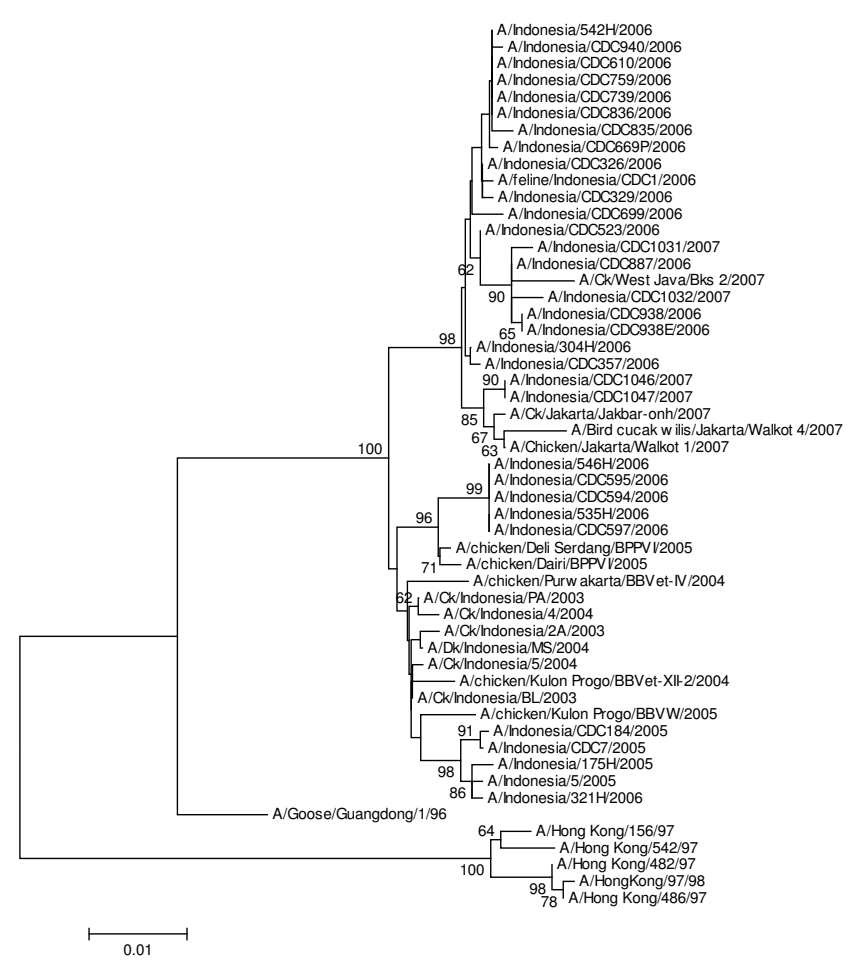

Fig 6 Phylogenetic tree of $\mathrm{M}$ gene of influenza H5N1 viruses from human and animal. All of the viruses used have same group with most of Indonesian H5N1 human isolates in 2006-2007.

this study do not show genetic closeness to the AI viruses of avian or animal origins. The A/Ck/Jakarta/Walkot1/2007, A/Bird Cucak Wilis/Jakarta/Walkot 4/2007, A/Ck/Jakarta/ Jakbar-onh/2007 and A/Ck/West Java/Bks2/2007 viruses significantly show genetic closeness to most of the human origin AI viruses used in this study. The A/Ck/West Java/ $\mathrm{Bks} 2 / 2007$ virus consistently shows its closeness to virus the A/Indonesia/CDC1031/2007 virus (Fig 6). The Virus /Ck/ Jakarta/Walkot 1/2007 and A/Bird Cucak Wilis/Jakarta/Walkot 4/2007 viruses have two different amino acids which are 45 and 77, even though these two viruses were collected from near by location. The differences may be caused by two different species, namely birds and chicken (Data not shown).

The amino acids that are related to the zinc finger motive domain are Cysteine, Alanine, Threonine, Cysteine, Glutamic, Glutamine, Isoleucine, Alanine, Aspartic, Serine, Glutamine, Histidine, Arginine, Serine, and Histidine (CATCEQIADSQHRSH) and are located at amino acid numbers 148 to 162 do not show differences. Similarly, the amino acids at numbers 101 to 105 consist of Lysine, Leucine,
Lysine and Arginine (KKLKR) as all isolates have the nuclear localization signal (NLS) (Data not shown).

The sensitivity to amantadine can be shown at the Matrix protein, precisely, on M2 protein, which is the presence of amino acids substitutions at positions 26 (Leu $\rightarrow$ Phe), 27 $(\mathrm{Val} \rightarrow$ Ala or Thr), 30 (Ala $\rightarrow$ Thr or Val) and $31(\mathrm{Ser} \rightarrow \mathrm{Asn} /$ Arg) (Suzuki et al., 2003). This study (Fig 7) shows that Indonesia viruses have the mutation of Val27Ala, while several other isolates show two mutations (including the A/Ck/ Jakarta/Walkot1/2007, A/Bird Cucak Wilis/Jakarta/Walkot 4/ 2007, A/Ck/Jakarta/Jakbar-onh/2007 viruses) namely Val27Ala and Ser31Asn. The identification of the mutation of the M2 protein is presented in Figure 7. At positions 16 and 55 the M2 protein is Glu/E and Leu/L, which is the host specificity site (M2) of avian like-amino acid.

\section{DISCUSSION}

Molecular Analysis. Gene HA has a protein product namely protein hemaglutinin, whose function to bind receptors containing sialic acid on the cell surface. The main role of this protein is to determine the host restriction and virulence. It is also responsible to the penetration of the virus into the cytoplasm through the endocytotic process. The results of this study showed that four viruses from avian species used in this study and the amino acid hemaglutinin sequence data obtained from GenBank have the receptor for avian as they still recognize $\alpha-2,3$ sialic acid. The AI virus in chicken which was analyzed throughout 2006, still showed the avian receptor. This shows that the transmission of AI virus in human still comes from avian species, and does not show the inter-human transmission. This is similar to the $\mathrm{H} 5 \mathrm{~N} 1$ virus that infected and caused fatalities to human in Hong Kong in 2007, and it constantly shows specificity of $\alpha-2,3$ sialic acid not $\alpha-2,6$ sialic acid receptor (Suzuki 2003; Harvey et al. 2004).

The error-prone activity of RNA polymerase causes the HA of AI virus to have a very high average mutation. The mutation was estimated that approximately $2 \times 10^{-3}$ base substitutions per position per virus generation or one base substitution on HA gene per virus generation. The selection of amino acid substitution is at least controlled by the immunological pressure as HA which is the main target of the host immune response. Even though HA is a molecule that mutates very rapidly, the amino acids at the HA receptor binding site (mostly are proline and cysteine) are conserved. In nature, there are at least $16 \mathrm{HA}$ subtypes (H1, H2, etc) which differ around $30 \%$ at the amino acid sequence at HA1
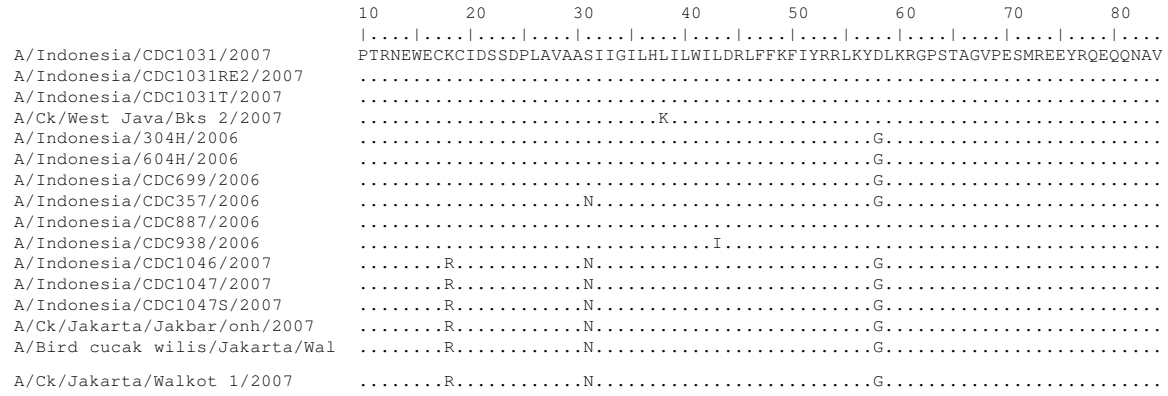

Fig 7 Multiple alignment of amino acid of M2 protein of AIV surrounding AI human cases. 
and which serologically do not cross-react (Webster et al. 1992; Fouchier et al. 2005). In this study, it was also proved that although there were mutations of several parts of the HA gene, the receptor binding site of the HA gene does not alter.

The phylogenic tree analysis on HA shows that only one virus, the $\mathrm{A} / \mathrm{Ck} / \mathrm{West} \mathrm{Java} / \mathrm{Bks} 2 / 2007$ that is in the same group as the sequencing data of from the human case. The A/Ck/ West Java/Bks2/2007 virus does not have closeness to the animal origin isolate analyzed in this study. Even the A/Ck/ West Java/Bks2/2007 virus has almost the same amino acid composition as the AI virus of human-origin, the the A/ Indonesia/CDC1031/2007. The phylogenetic analysis showed that the AI viruses in Indonesia are divided into several groups depending on the extent of mutation occurring in the viruses. Different from the HA gene, the NA and NS genes are still in the same group, which shows that they have not experienced significant changes or mutation. The relationship based on the NA and NS genes on the phylogenetic analysis shows that Indonesian isolates have not yet altered. From the phylogenetic analysis of NA and NS genes, the A/Ck/West Java/Bks2/2007 virus constantly shows its closeness to the A/Indonesia/CDC1031/2007 virus.

The amino acid composition of NA, NS and M does not alter much, even the A/Ck/West Java/Bks2/2007 virus has similar amino acid composition to the NA protein with the A/ Indonesia/CDC1031/2007 virus. All virus isolates observed including the $\mathrm{AI}$ amino acid sequencing data of human-origin have the amino acid composition at zinger finger motif, namely at positions 148 to 162 of the M1 gene. In addition, the nuclear localization signal (NLS) at positions 101 to 105 is also possessed by all viruses analyzed in this study.

At the NS1 level, the NS1 protein plays an important role in the pathogenicity of the H5N1 virus in different hosts. A deletion of five amino acid residue at positions 80 to 84 was found in the NS1 molecule of the viruses used in this study, including other Indonesian viruses. The ESEV motif is the PDZ-ligand binding motif which is found in all the viruses used showed that all Indonesian viruses were avian origin. They are able to bind cellular PDZ-containing proteins involved in host cellular signaling pathways. In contrast, the NS1 protein in most low pathogenic human influenza viruses contain a different motif (RSKV or RSEV), which cannot bind PDZ-containing proteins. A recent study showed that the PDZ-binding motif of NS1 is a new virulence factor of influenza A viruses (Jackson et al. 2008).

Amantadine Resistant of the Viruses. The sensitivity against amantadine that can be detected from M2 protein, shows that the four AI virus isolates used in this study experienced mutation at the matrix gene which is the transmembrane domain. Li et al (2004) stated that most of the H5N1 strains isolated in South East Asia are resistance to amantadine and rimantadine, the antiviral group used to cure and prevent the infection by virus influenza $A$. These drugs inhibit the viral replications at the initial stadium of the infection by inhibiting the ion channel formed by M2 protein. The substitution of one of the five amino acids (at positions $26,27,30,31$ and 34) in the domain of transmembrane $M 2$ is implicated by the missing of inhibiting sensitivity by M2 (Hay et al. 1985 ; Pinto et al.1992).
The virus mutation against amantadine has excessively been reported especially in Thailand and Vietnam (almost 95\%). Cheung et al (2006) stated that most of the Indonesian viruses are still sensitive to amantadine only about $6.3 \%$ while in China it is $8.99 \%$. The Indonesia viruses isolated in 2007 were analyzed and the results showed an increase of virus numbers resistant to amantadine. Most viruses resistant to adamantane (amantadine and rimantadine), approximately $70-80 \%$, have the mutation at position 31 on the M2 protein (Bright et al. 2006). This was also shown by the results in this study, where 3 out of 4 viruses analyzed had the mutation at position 31. In this study, all of the viruses analyzed had mutation at position 26 .

The Correlation between H5N1 Avian Viruses and Human Viruses. The analysis conducted on the AI virus isolates of avian-origin from the surrounding of humans infected by the AI virus showed that only one virus from four viruses, A/Ck/West Java/Bks2/2007 has the genetic closeness of the HA, NA, M and NS genes to the humanorigin virus, which is the $\mathrm{A} / \mathrm{Indonesia/CDC1031/2007} \mathrm{virus.}$ The data from the GenBank show that the A/Indonesia/ CDC1031/2007 virus was collected in January 2007 from a boy of 14 years old. Similar information about the A/Ck/ West Java/Bks2/2007 virus was obtained when collecting samples was conducted. In fact this virus was taken from live chicken/bird from the AI outbreak that happened a week before the human case in the surrounding location. However, whether the virus is actually taken from the location of the A/ Indonesia/CDC1031/2007 case, until this publication is written, no information was obtained regarding this. Therefore, it is necessary to have coordination between the Department of Agriculture (AARD) and the Department of Health (AHRD) especially for collecting samples together when there was a case in human. The Department of Agriculture or the local Livestock Services was frequently late in collecting samples when some human cases occurred; therefore, it is never known which virus characters of avianorigin can infect human.

The A/Ck/Jakarta/Walkot 1/2007 and A/Bird Cucak Wilis/ Jakarta/Walkot 4/2007 viruses were isolated from the AI suspect cases without any information whether the cases were confirmed or not. The A/Ck/Jakarta/Jakbar-onh/2007 virus was collected from the area surrounding the confirmed case, but this was not from the house or the surrounding of the victim. Virus A/Ck/Jakarta/Jakbar-onh/2007 was taken from samples collected from the victim neighbor, but in a different administration unit (RT). From the molecular analysis conducted, these three viruses (A/Ck/Jakarta/Walkot1/2007, A/Bird Cucak Wilis/Jakarta/Walkot4/2007 and A/Ck/Jakarta/ Jakbar-onh/2007 viruses) did not show their genetic closeness to the 2007 human-origin virus; however, it was closer to the 2005-2006 human-origin virus and the escape mutant virus from chicken intensive commercially farm. The closeness of these three viruses was only the at the Matrix Gene with the A/Indonesia/CDC1046/2007 and A/Indonesia/CDC1047/2007 isolates.

The very significant closeness and similarity between the A/Ck/West Java/Bks2/2007 and A/Indonesia/CDC1031/ 2007 viruses at the molecular levels, although not accompanied by sufficient information regarding the similarity 
of locations and time for the two isolates of avian and humanorigins. This emphasizes that most AI infection cases in humans come from avian species.

\section{ACKNOWLEGMENT}

Appreciation is conveyed to the livestock services at Bekasi Regency and the Veterinary and Fisheries Institute in Jakarta for all the help provided during the sample collection. Gratitude is also extended to Nana Suryana and Teguh Suyatno for their technical assistance during the study. This research was funded by the 2008 Intensive Program of Research and Technology, the Ministry of Research and Technology.

\section{REFERENCEES}

Bright RA, Shay DK, Shu B, Cox NJ, Klimov AI. 2006. Adamantane resistance among influenza A viruses isolated early during the 20052006 influenza season in the United Stated. JAMA 295:891-4.

Cheung CL, Rayner JM, Smith GJD, Wang P, Naipospos TSP, Zhang J, Yuen KY, Webster RG, Peiris JSM, Guan Y, Chen H. 2006. Distribution of Amantadine-resistant H5N1 avian influenza variants in Asia. J Infec Dis 103:1626-9.

Dharmayanti NLPI, Indriani R, Damayanti R, Wiyono A. 2005a. Isolation and identification of avian influenza outbreak in October 2004-March 2005 in Indonesia. J Biol Indon 9:341-50.

Dharmayanti NLPI, Damayanti R, Indriani R, Wiyono A, Adjid RMA. 2005b. Molecular Characterization of Indonesia avian influenza virus. JITV 10:127-33.

Dharmayanti NLPI, Damayanti R, Indriani R, Wiyono A, Adjid RMA. $2005 \mathrm{c}$. Indonesian avian influenza viruses character in second wave the outbreaks. JITV 10:217-26.

Dharmayanti NLPI, Indriani R, Adjid RMA. 2006. Identification and eradication avian influenza virus in some birds in Taman Margasatwa Ragunan. MKH 22:79-83.

Fouchier RAM, Munster V, Wallensten A, Bestebroer TM, Herfst S, Smith D, Rimmelzwaan GF, Olsen B, Osterhaus ADME. 2005.
Characterization of novel influenza A virus hemaglutinin subtype (H16) obtained from black-headed gulls. J Virol 79:2814-22.

Harvey R, Martin ACR, Zambon M, Barclay W. 2004. Restriction to the adaptation of influenza A virus H5 hemaglutinin to the human host. J Virol 78:502-7.

Hay AJ, Wolstenholme AJ, Skehel JJ, Smith MH. 1985. The molecular basis of the specific anti-influenza action of amantadine. EMBO J 4:3021-4.

Hoffmann E, Stech J, Guan Y, Webster RG, Perez DR. 2001. Universal primer set for the full-length amplification of all influenza A viruses. Arch Virol 146:2275-89.

Holland J, Spindler K, Horodyski F, Grabau E, Nichol S, VandePol S. 1982. Rapid evolution of RNA genomes. Science 215:1577-85.

Jackson D, Hossain MJ, Hickman D, Perez DR, Lamb RA. 2008. A new influenza virus virulence determinant: the NS1 protein four C-terminal residues modulate pathogenicity. Proc Natl Acad Sci USA 105:4381-6.

Li KS, Guan Y, Wang J, Smith GJD, Xu KM, Duan L, Rahardjo AP, Puthavathana P, Buranathai C, Nguyen TD, Estoepangestie ATS, Chaisingh A, Auewarakul P, Long HT, Hanh NTH, Webby RJ, Poon LLM, Chen H, Shortridge KF, Yuen KY, Webster RG, Peiris JSM. 2004. Genesis of a highlypathogenic and potentially pandemic H5N1 influenza virus in eastern Asia. Nature 430:20913.

Obenauer JC, Denson J, Mehta PK, Su X, Mukatira S, Finkelstein DB, Xu X, Wang J, Ma J, Fan Y, Rakestraw KM, Webster RG, Hoffmann E, Krauss S, Zheng J, Zhang Z, Naeve CW. 2006. Large-scale sequence analysis of avian influenza isolates. Science 311:157680 .

OIE. 2000. Manual of standards for diagnostic tests and vaccines. 212-219.

Suzuki H, Saito R, Masuda H, Oshitani H, Saito M, Sato I. 2003. Emergence of amantadine-resitstant influenza A viruses: epidemiological study. J Infect Chemother 9:195-200.

Steinhauer DA, Holland JJ. 1987. Rapid evolution of RNA viruses. Annu Rev Microbiol 41:409-33.

Pinto LH, Holsinger LJ, Lamb RA. 1992. Influenza virus M2 protein has ion channel activity. Cell 69:517-28.

Webster RG, Bean WJ, Gorman OT, Kawaoka Y. 1992. Evolution and ecology of influenza A viruses. Microbiol Rev 56:152-79. 